Article

\title{
Global Aquaculture Performance Index (GAPI): The First Global Environmental Assessment of Marine Fish Farming
}

\section{John P. Volpe *, Jennifer L.M. Gee, Valerie A. Ethier, Martina Beck, Amanda J. Wilson and Jenna M.S. Stoner}

Seafood Ecology Research Group, School of Environmental Studies, University of Victoria, PO Box 1700 STN CSC, Victoria, BC V8W 2Y2, Canada; E-Mails: jgee@uvic.ca (J.L.M.G.); vethier@uvic.ca (V.A.E.); mbeck@uvic.ca (M.B.); ajw@uvic.ca (A.J.W.); jstoner@uvic.ca (J.M.S.S.)

* Author to whom correspondence should be addressed; E-Mail: jpv@uvic.ca; Tel.: +1-250-472-4298; Fax: +1-250-721-8985.

Received: 16 July 2013; in revised form: 23 August 2013 / Accepted: 23 August 2013 / Published: 17 September 2013

\begin{abstract}
Sustainable" is among the most sought after of all seafood product adjectives. Ironically it is also one of the most poorly defined and understood. The Global Aquaculture Performance Index (GAPI) is the first tool to assess environmental performance of global marine aquaculture production, permitting direct comparison of disparate species, production methods and jurisdictions. Clear patterns emerge from this analysis; significant variation of environmental performance is driven by the species being farmed, significant room for improvement exists across the entire sector, the worst performing players are also the fastest growing, particularly within Asia, and perhaps most importantly, this work highlights the potential trap awaiting policy makers who focus too narrowly on farm production efficiency alone as a solution to diminishing seafood availability.
\end{abstract}

Keywords: aquaculture; efficiency; marine ecology; performance metrics; seafood; sustainable production

\section{Introduction}

With over $87 \%$ of global capture fisheries currently fully- or over-exploited [1] aquaculture is looked upon with increasing urgency to fill the growing global demand for seafood. Over the past three 
decades the growth of aquaculture production has exceeded all other agricultural sectors worldwide (8.8\% annual compounded growth since 1980) [1]. Such rapid growth does not come without challenges and production related environmental impacts are diverse and well documented [2-4]. To further complicate matters, while overall production grows rapidly so too does the diversity of species being brought into culture [1] thus amplifying the breadth of potential aquaculture $\times$ environment interactions.

Seafood is among the most global of commodities with international imports dominating seafood consumption in most developed nations [1]. Environmentally conscious buyers of aquaculture products face a complex calculus in determining how differing species, production regions and production systems all affect "sustainability" of the product. In response, a de facto sustainable seafood industry has arisen, aiding buyers, both wholesale and retail, in making informed conservation choices. A review of 63 market-based initiatives concluded the lack of coherence across the plethora of guides, standards and certifications is confusing buyers and the lack of demonstrably improved performance on the water undermines the potential efficacy of the entire approach [5].

In order to bring clarity to the myriad species, locales and production methods characterizing modern aquaculture we adopted the analytical foundation of the Environmental Performance Index (EPI) [6]. The EPI is a globally recognized statistical framework which scores environmental performance of all recognized countries against 10 core environmental issue areas. Each issue area yields a performance score that is the weighted aggregate of multiple independent metrics. EPI country rankings are presented biennially at the World Economic Forum meeting in Davos, Switzerland, and have had a transformative effect on the way global environmental performance is measured and compared. Our tool, retrofitted specifically for assessment of marine finfish aquaculture products is the Global Aquaculture Performance Index (GAPI). Like the EPI, GAPI indicates which products perform best across an array of environmental criteria allowing users to drill down to assess performance within each species, producing country, or individual issue areas. In so doing, clear environmental leaders and laggards (both species and countries) are made apparent. Perhaps most importantly, best performing combinations of species, countries and production systems are identified, and provide clear templates of improvement for those lagging behind.

Quantifying environmental performance of aquaculture production has historically proven difficult, reflecting scarcity of data, inconsistent reporting, incomplete science, and a wide range of potential environmental impacts across a global distribution of production. As significant as these challenges may be, they are insufficient to excuse inaction. However, prerequisite to addressing the challenge is creation of a baseline "state of the industry" performance snapshot designed for clear policy relevance.

\section{Experimental Section}

\subsection{Which Metrics Should Be Included and How to Measure Each?}

Literally hundreds of metrics could conceivably be employed in the assessment of aquaculture environmental performance, but which should be and how should inclusion/omission be decided? A pilot survey of current seafood sustainability initiatives was undertaken to determine what suite of performance criteria should be included in the GAPI assessment tool. Issues addressed repeatedly across initiatives are, by consensus, considered to be significant and strong candidates for inclusion 
here. We assessed 30 aquaculture sustainability schemes active in North America and Western Europe (Appendix A). Ten issue areas were consistently addressed across initiatives. These 10 markers of environmental performance (Table 1) were deemed the minimum necessary suite of indicators required for comprehensive assessment of global marine aquaculture and are in fact the product of a de facto peer review by the sustainable seafood community. To determine performance on a 0 to 100 scale as we have done, absolute best (100) and worst (0) performance must first be defined. A perfect score of 100 equates to absolutely no measurable environmental impact. Perfection (absolutely no impact in each of the 10 criteria) is clearly unattainable but the closer a player comes, the higher the score. Determining the worst performance (a score of 0 ) is more complicated. Theoretically, a given product could perform infinitely poorly within one or all indicators. For instance, what would be the worst possible performance for antibiotic or parasiticide use? The scope is, at least theoretically, infinite. To solve this dilemma, GAPI reviews the pool of performances for that indictor and sets " 0 " as the worst observed actual performance. Thus, like a classroom grading system, GAPI grades on a curve, where a performer's GAPI score is partially dependent on the performance of the pool of players among which it is being assessed. This is consistent with the objective of the tool, which is to generate performance profiles that are informative for making comparisons of two or more products. A further implication is that a GAPI score is only informative relative to another score. GAPI is not a standard with a threshold above which a product is considered "sustainable". Rather GAPI scores reveal strengths and weaknesses in environmental performances relative to other players, and thus avoids the false simplicity of a single absolute sustainability threshold.

Table 1. The 10 Global Aquaculture Performance Index (GAPI) indicators with a brief description and formula for each.

\begin{tabular}{|c|c|c|}
\hline Criteria & Criteria Description & Criteria Equation \\
\hline Antibiotic & $\begin{array}{l}\text { Amount of antibiotics used, weighted by a } \\
\text { measure of human and animal health risk. }\end{array}$ & $\frac{\sum \text { (Amount Active Ingredient }(\mathrm{kg}) \times}{\frac{\text { WHO-OIE Score })}{\text { mT Fish Produced }}}$ \\
\hline $\begin{array}{l}\text { Antifoulants } \\
\text { (Copper) }\end{array}$ & $\begin{array}{l}\text { Estimated proportion of production using } \\
\text { copper-based antifoulants. }\end{array}$ & $\frac{\left(\mathrm{BOD}\left(\mathrm{mg} \mathrm{O}_{2}\right) * \text { Area of Impact }\left(\mathrm{km}^{2}\right)\right)}{\text { mT Fish Produced }}$ \\
\hline $\begin{array}{c}\text { Biochemical } \\
\text { Oxygen Demand } \\
\text { (BOD) } \\
\end{array}$ & $\begin{array}{l}\text { Relative oxygen-depletion effect of waste } \\
\text { contaminants (uneaten feed and feces). }\end{array}$ & $\begin{array}{c}\sum \text { (Amount }(\mathrm{kg}) \times[(1 / \mathrm{LC} 50)+1] * \text { Persistence } \\
\underline{(\text { Days }))} \\
\text { mT Fish Produced }\end{array}$ \\
\hline $\begin{array}{l}\text { Capture-Based } \\
\text { Aquaculture }\end{array}$ & $\begin{array}{l}\text { The extent to which a system relies on the } \\
\text { capture of wild fish for production, taking } \\
\text { into account the sustainability of these wild } \\
\text { fish inputs. }\end{array}$ & 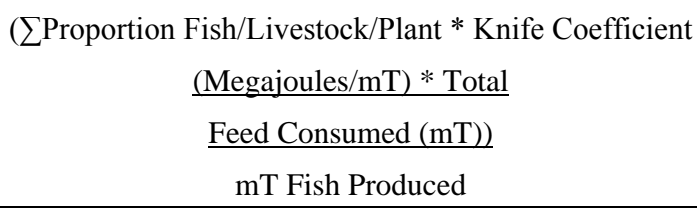 \\
\hline Ecological Energy & $\begin{array}{l}\text { Amount of energy, or net primary } \\
\text { productivity (NPP), that farmed fish divert } \\
\text { from the marine ecosystem through } \\
\text { consumption of wild fish ingredients of feed }\end{array}$ & $\begin{array}{c}\sum \text { Net Primary Production of } \\
\frac{\text { Feed Inputs (g carbon } / \mathrm{kg} \text { ) }}{\mathrm{mT} \text { Fish Produced }}\end{array}$ \\
\hline
\end{tabular}


Table 1. Cont.

\begin{tabular}{|c|c|c|}
\hline Criteria & Criteria Description & Criteria Equation \\
\hline Escapes & $\begin{array}{l}\text { Number of escaped fish, weighted by an } \\
\text { estimate of the per capita risk associated } \\
\text { with escapes. }\end{array}$ & $\begin{array}{c}\sum \text { Pathogen-specific Wild Losses (mT) } \\
\text { mT Fish Produced }\end{array}$ \\
\hline Industrial Energy & $\begin{array}{l}\text { Energy consumed in the acquisition and } \\
\text { processing of feed ingredients, which serves } \\
\text { as a proxy for the total industrial energy } \\
\text { used in production. }\end{array}$ & $\begin{array}{c}\sum \text { (Amount from Wild Capture } \\
\frac{(\mathrm{kg}) * \text { Sustainability Score })}{\mathrm{mT} \text { Fish Produced }}\end{array}$ \\
\hline Parasiticide & $\begin{array}{l}\text { Amount of parasiticides used, weighted by } \\
\text { measures of environmental toxicity and } \\
\text { persistence. }\end{array}$ & $\begin{array}{c}\text { (Production }(\mathrm{mT}) * \% \text { Production } \\
\frac{\text { Using Copper-based Antifoulants) }}{\mathrm{mT} \text { Fish Produced }} \\
\end{array}$ \\
\hline Pathogens & $\begin{array}{l}\text { Number of on-farm mortalities, weighted } \\
\text { by an estimate of wild species in the } \\
\text { ecosystem that are susceptible to } \\
\text { farm-derived pathogens. }\end{array}$ & $\begin{array}{c}\sum(\text { Amount }(\mathrm{kg}) \times[1 / \mathrm{LC} 50+1 \times \\
\text { Persistence } \underline{(\text { days })]} \\
\text { mT Fish Produced }\end{array}$ \\
\hline $\begin{array}{l}\text { Sustainability } \\
\text { of Feed }\end{array}$ & $\begin{array}{l}\text { Amount, efficiency, and sustainability of } \\
\text { wild fish ingredients of feed. }\end{array}$ & $\begin{array}{c}\sum((\text { Proportion of Feed by Species * } \\
\text { Sustainability Score of Each } \underline{\text { Species }) *} \\
\frac{\text { Fish In: Fish Out Ratio * Production }(\mathrm{mT}))}{\text { mT Fish Produced }}\end{array}$ \\
\hline
\end{tabular}

* GAPI takes the square root of each indicator formula to make the range of performance values more manageable and disperse the final scores so that differences are more apparent.

Following the identification of the 10 issues which were to become the focus of GAPI, the next step was developing the analytical framework to measure on-the-water performance. Deriving metrics capable of capturing all marine finfish aquaculture production globally is a significant undertaking. Numerous expert workshops were convened, each focused on developing and refining specific ecological indicators. This ensued a multiyear process cumulatively involving substantial input from more than 30 experts, including biologists, producers, statisticians, seafood buyers, and individuals engaged in sustainability assessment. The consensus products of these workshops are presented in Table 1.

Since final GAPI scores are informed by the pool of country-species assessed, it is critical that the pool is representative of the entire peer group. In 2007, 82 marine finfish species or species groups were farmed in 62 countries (FAO 2008a). However, production was dominated by a relatively small number of species. The present assessment was restricted to the top 20 species by production (Table 2), which cumulatively constituted $98.5 \%$ of all marine finfish aquaculture production. The remaining $1.5 \%$ of global production is spread across an additional 39 species. Just as a small number of species comprise the majority of production, the same is true for producing countries. A species may be farmed in numerous countries but typically the great majority of production occurs in only a few. Thus only those countries that together comprised the top $90 \%$ of production of each of the 20 selected species were included. These two decision rules resulted in an assessment of 20 marine finfish species being produced in 22 producing countries which together comprise $94 \%$ of marine finfish production by weight (mT) and $91 \%$ by value (USD) [7]. 
Table 2. Species assessed by GAPI in descending order of 2007 production volume.

\begin{tabular}{|c|c|c|c|c|}
\hline $\begin{array}{l}\text { Species } \\
\text { Rank } \\
(\mathbf{m T})\end{array}$ & $\begin{array}{l}\text { Marine Finfish Species } \\
\text { (in production in 2007) }\end{array}$ & $\begin{array}{l}\% \text { of Global } \\
\text { Marine Finfish } \\
\text { Production } \\
\text { by Weight }\end{array}$ & $\begin{array}{l}\% \text { of Global } \\
\text { Marine Finfish } \\
\text { Production } \\
\text { by Value }\end{array}$ & $\begin{array}{l}\text { Producing Countries Included in } \\
\text { GAPI Analysis (Representing 90\% } \\
\text { of Species Production) }\end{array}$ \\
\hline 1 & Atlantic salmon & 40.8 & 50 & Canada, Chile, Norway, UK \\
\hline 2 & Milkfish & 17.1 & 4.6 & Indonesia, Philippines \\
\hline 3 & Flathead grey mullet & 6.7 & 3.8 & Egypt \\
\hline 4 & Japanese amberjack & 4.9 & 9 & Japan \\
\hline 5 & Red seabream & 3.8 & 3.7 & China, Japan \\
\hline 6 & Gilthead seabream & 3.5 & 4.7 & Greece, Israel, Italy, Spain, Turkey \\
\hline 7 & Coho salmon & 3.3 & 3 & Chile, Japan \\
\hline 8 & Bastard halibut & 3.2 & 4.1 & China, Korea \\
\hline 9 & European seabass & 3 & 4.3 & Greece, Italy, Spain, Turkey \\
\hline 10 & Japanese seabass & 2.9 & 0.9 & China \\
\hline 11 & Groupers & 2 & 1.4 & China, Indonesia, Taiwan \\
\hline 12 & Large yellow croaker & 1.8 & 0.5 & China \\
\hline 13 & Red drum & 1.5 & 0.5 & China \\
\hline 14 & Korean rockfish & 1 & 1.4 & Korea, Australia, Indonesia, Malaysia \\
\hline 15 & Barramundi & 0.9 & 0.6 & Thailand \\
\hline 16 & Cobia & 0.8 & 0.4 & China, Taiwan \\
\hline 17 & Tiger pufferfish & 0.5 & 0.7 & China, Japan \\
\hline 18 & Atlantic cod & 0.3 & 0.3 & Iceland, Norway \\
\hline 19 & Chinook salmon & 0.3 & 0.5 & Chile, New Zealand \\
\hline \multirow[t]{3}{*}{20} & Turbot & 0.2 & 0.4 & France, Spain \\
\hline & $\begin{array}{l}\text { Total \% of Global Marine } \\
\text { Finfish production }\end{array}$ & 98.5 & 95 & \\
\hline & $\begin{array}{l}\text { \% of Global Marine } \\
\text { Finfish production assessed } \\
\text { by GAPI }\end{array}$ & 93.7 & 91 & \\
\hline
\end{tabular}

\subsection{Deriving the GAPI Score}

The derivation of the final GAPI score for each species-country pair assessed (e.g., Atlantic salmon-Norway) consists of eight steps (full methodology detailed in Appendices A and B as well at Global Aquaculture Performance Index).

\subsubsection{Select Key Indicators of Environmental Performance}

Emphasis has been placed on identifying a suite of indicators that sufficiently describes the major ecological impacts of marine finfish aquaculture while using the fewest indicators possible. Details of the pilot study and the resulting indicator selection process are presented in Appendix A. 


\subsubsection{Construct Indicator Metrics}

In order to determine how to best measure actual performance we developed specific criteria to ensure that each is:

- relevant and measures direct environmental impact;

- performance oriented and tracks actual, on-the-water performance; (as opposed to aspirational or "best practice")

- transparent (both formulae and data); and

- utilizes the highest quality data available

Details of the process are presented in Table 1 and Appendix B. The derivation of issue-specific metrics is detailed in Appendix C.

\subsubsection{Set Targets for Each Indicator}

By setting a zero-impact target for each indicator, GAPI permanently sets the environmental performance at the ecological ideal rather than continually recalibrating the goal as the performance of the industry improves or as viewpoints of what is an "acceptable" level of impact shift.

\subsubsection{Collect Data}

A wide range of data drawn from international organizations, regulatory bodies, conservation organizations, academia, seafood industry groups, and seafood industry trade press were used. All data used are publicly available and traceable. Details of the process are presented in Appendix A. This step represents significant effort not only in acquisition but quality assessment and standardization of data and explains the time lag between production date and scoring.

\subsubsection{Winsorization}

Winsorization is a common statistical approach [8] to dealing with extreme outliers so those values do not distort the distribution of the entire data set. This is important to maintain the legitimacy of the dataset. Details of the process are presented in Appendix B.

\subsubsection{Proximity-to-Target Calculation}

In order to directly compare performance among two or more disjunct indicators (i.e., escaping fish and the sustainability of feed sources) in a statistically meaningful way, it is necessary to standardize performance for each on the same 0 -to-100 scale. Proximity-to-target calculations quantify how close a performer is to meeting zero-impact for each of the 10 indicators. Details of this process are presented in Appendix B.

\subsubsection{Weighting Indicators}

The 10 indicators included within GAPI have already been deemed by the conservation community to be important drivers of environmental performance (Appendix A). Principal component analysis 
(PCA) measures how much of the total variation in the data is explained by each indicator, thus providing a measure of each indicator's relative importance or weight (Table 3). To be clear, PCA does not ascribe "importance". Any user-defined combination of weights would ultimately be subjective. Likewise, assigning equal weights to each of the 10 indicators is itself a subjective weighting. Indeed, indicators used in sustainability assessments typically reflect subjective judgments without mentioning or systematically assessing critical assumptions [9]. The PCA approach ascribes weight according to that criteria's capacity to separate leaders from laggards; an objective statistical technique absent any investigator influence. Details of the process are presented in Appendix B.

Table 3. Example calculation of the final normalized GAPI score for tiger puffer fish produced in China.

\begin{tabular}{l|l|l|l|l|}
\hline \multicolumn{1}{c|}{ A } & \multicolumn{1}{c|}{ B } & \multicolumn{1}{c|}{ C } & \multicolumn{1}{c}{ D } \\
\hline Indicator & $\begin{array}{l}\text { Indicator } \\
\text { Performance }\end{array}$ & $\begin{array}{l}\text { PCA Derived } \\
\text { Weight }(\%)\end{array}$ & $\begin{array}{l}\text { Weighted Performance } \\
\text { PCA Weight (\%) } \times \\
\text { Indicator Performance) }\end{array}$ & $\begin{array}{l}\text { GAPI Score (Sum of } \\
\text { Weighted Performances) }\end{array}$ \\
\hline ANTI & 37 & 15 & 5.6 \\
\hline BOD & 72 & 8.3 & 3.7 \\
\hline CAP & 100 & 5 & 5.1 \\
\hline COP & 28 & 5 & 2.3 \\
\hline ESC & 66 & 15 & 9.8 \\
\hline FEED & 11 & 8.3 & 3.9 \\
\hline INDE & 60 & 8.3 & 1.6 \\
\hline PARA & 84 & 15 & 5 \\
\hline PATH & 3 & 5 & 4.3 \\
\hline
\end{tabular}

Note: First, the performer's environmental performance within each indicator (Columns A and B) is determined by calculating the proximity-to-target for each normalized indicator and standardized on a scale of 0 (worst) to 100 (no impact) (Column C). The weight that each of these indicators contributes to the final score is then calculated using Principal Component Analysis (PCA) (Column D). The product of indicator performance (Column C) and PCA-derived weight, expressed as a percentage (Column D) yield the weighted indicator performance (Column E). The final GAPI score (Column F), which describes China's normalized tiger puffer fish aquaculture performance, is the sum of the 10 weighted performance scores in Column E.

\subsubsection{Calculating the Final Country Score}

The final score is the sum of the 10 criteria scores post-PCA weighted. GAPI reports two scores for each product: a normalized score and a cumulative score.

Normalized scores are standardized to reflect environmental performance per mT of production (Table 3). Normalized scores reflect the inherent production profile of that species and are not influenced by scale of production (as are cumulative scores). Because impacts are standardized per mT of production, policy relevant questions may be asked directly; How does a species produced in one country compare to other countries producing the same species? Which species score consistently poorly and which consistently well and why? What specific dimensions of performance can most 
immediately and cost effectively be improved and which jurisdictions may provide a template for doing so (based on their superior score)?

For instance, China scores particularly poorly in biological oxygen demand (BOD), ecological energy consumption (ECOE) and feed use (FEED) relative to other countries (Table 4). Resources are more likely to yield substantive performance improvement if targeted at one or more of these areas rather than escapes (ESC) or parasiticides (PARA), where China scores relatively well and therefore the scope for improvement is more modest. Normalized scores encourage policymakers to think about regulations that can improve the relative performance of the industry. They provide an "apples to apples" comparison against other industries or countries, regardless of their size.

Table 4. Criteria scores contributing to the overall normalized scores. Cell shading indicates criteria group; Inputs (none), Outputs (light) and Biological (dark) criteria.

\begin{tabular}{|c|c|c|c|c|c|c|c|c|c|c|c|c|}
\hline Species & Country & $\begin{array}{c}\text { Overall } \\
\text { Score } \\
\end{array}$ & CAP & ECOE & FEED & INDE & ANTI & BOD & COP & PARA & ESC & PATH \\
\hline Atlantic Cod & Norway & 62 & 100 & 64 & 68 & 58 & 98 & 59 & 28 & 45 & 0 & 63 \\
\hline Atlantic Cod & Iceland & 69 & 100 & 64 & 68 & 58 & 98 & 92 & 28 & 88 & 0 & 87 \\
\hline Atlantic Salmon & Chile & 66 & 100 & 72 & 75 & 62 & 68 & 81 & 28 & 77 & 38 & 67 \\
\hline Atlantic Salmon & Canada & 70 & 100 & 74 & 75 & 57 & 90 & 66 & 28 & 99 & 39 & 72 \\
\hline Atlantic Salmon & UK & 72 & 100 & 66 & 75 & 60 & 96 & 61 & 49 & 53 & 40 & 86 \\
\hline Atlantic Salmon & Norway & 72 & 100 & 75 & 75 & 64 & 99 & 50 & 28 & 84 & 40 & 78 \\
\hline Barramundi & Thailand & 41 & 100 & 39 & 44 & 40 & 38 & 0 & 28 & 40 & 35 & 46 \\
\hline Barramundi & Indonesia & 46 & 100 & 39 & 44 & 40 & 42 & 94 & 28 & 5 & 35 & 57 \\
\hline Barramundi & Australia & 47 & 100 & 70 & 65 & 0 & 58 & 62 & 28 & 30 & 35 & 24 \\
\hline Barramundi & Malaysia & 50 & 100 & 39 & 44 & 40 & 77 & 75 & 28 & 0 & 35 & 57 \\
\hline Bastard Halibut & China & 41 & 100 & 59 & 34 & 61 & 37 & 39 & 28 & 69 & 49 & 0 \\
\hline Bastard Halibut & Korea, & 61 & 100 & 51 & 42 & 23 & 82 & 44 & 100 & 4 & 100 & 57 \\
\hline Chinook Salmon & Chile & 64 & 100 & 75 & 75 & 55 & 68 & 98 & 28 & 64 & 42 & 53 \\
\hline Chinook Salmon & New Zealand & 73 & 100 & 70 & 52 & 43 & 100 & 100 & 28 & 100 & 47 & 100 \\
\hline Cobia & Taiwan & 35 & 100 & 0 & 51 & 5 & 24 & 74 & 28 & 6 & 41 & 60 \\
\hline Cobia & China & 37 & 100 & 0 & 51 & 5 & 37 & 42 & 28 & 35 & 41 & 60 \\
\hline Coho Salmon & Japan & 56 & 100 & 68 & 62 & 61 & 13 & 68 & 28 & 79 & 34 & 77 \\
\hline Coho Salmon & Chile & 63 & 100 & 71 & 75 & 59 & 68 & 90 & 28 & 64 & 37 & 52 \\
\hline European Seabass & Turkey & 61 & 100 & 59 & 74 & 43 & 50 & 66 & 28 & 81 & 53 & 75 \\
\hline European Seabass & Spain & 63 & 100 & 60 & 69 & 47 & 57 & 93 & 31 & 78 & 49 & 75 \\
\hline European Seabass & Greece & 66 & 100 & 61 & 75 & 50 & 81 & 58 & 28 & 81 & 47 & 75 \\
\hline European Seabass & Italy & 69 & 100 & 61 & 72 & 31 & 64 & 97 & 64 & 81 & 74 & 75 \\
\hline Flathead Grey Mullet & Egypt & 71 & 68 & 67 & 99 & 57 & 32 & 79 & 100 & 81 & 41 & 91 \\
\hline Gilthead Seabream & Turkey & 55 & 100 & 75 & 69 & 55 & 50 & 66 & 28 & 81 & 5 & 44 \\
\hline Gilthead Seabream & Greece & 56 & 100 & 69 & 79 & 60 & 50 & 49 & 28 & 57 & 5 & 56 \\
\hline Gilthead Seabream & Spain & 57 & 100 & 69 & 72 & 57 & 50 & 90 & 31 & 56 & 8 & 56 \\
\hline Gilthead Seabream & Israel & 60 & 100 & 67 & 80 & 41 & 50 & 69 & 49 & 77 & 32 & 56 \\
\hline Gilthead Seabream & Italy & 65 & 100 & 67 & 81 & 37 & 50 & 98 & 64 & 81 & 53 & 56 \\
\hline Groupers & Indonesia & 10 & 0 & 0 & 0 & 0 & 0 & 85 & 28 & 6 & 32 & 3 \\
\hline Groupers & China & 15 & 0 & 0 & 0 & 0 & 37 & 21 & 28 & 47 & 35 & 3 \\
\hline Groupers & Taiwan & 28 & 0 & 41 & 45 & 39 & 24 & 58 & 28 & 0 & 35 & 3 \\
\hline Japanese Amberjack & Japan & 45 & 99 & 60 & 39 & 56 & 36 & 0 & 28 & 84 & 43 & 32 \\
\hline Japanese Seabass & China & 32 & 54 & 24 & 18 & 25 & 31 & 4 & 28 & 44 & 35 & 57 \\
\hline Korean Rockfish & Korea & 54 & 100 & 55 & 52 & 40 & 82 & 45 & 28 & 0 & 49 & 57 \\
\hline Lg Yellow Croaker & China & 41 & 100 & 23 & 33 & 27 & 31 & 37 & 28 & 89 & 48 & 57 \\
\hline
\end{tabular}


Table 4. Cont.

\begin{tabular}{|c|c|c|c|c|c|c|c|c|c|c|c|c|}
\hline Species & Country & $\begin{array}{c}\text { Overall } \\
\text { Score } \\
\end{array}$ & CAP & ECOE & FEED & INDE & ANTI & BOD & COP & PARA & ESC & PATH \\
\hline Milkfish & Phillippines & 59 & 98 & 78 & 90 & 57 & 69 & 37 & 28 & 0 & 46 & 39 \\
\hline Milkfish & Indonesia & 68 & 98 & 80 & 90 & 61 & 97 & 67 & 28 & 45 & 46 & 39 \\
\hline Red Drum & China & 26 & 100 & 0 & 4 & 5 & 37 & 21 & 28 & 49 & 37 & 37 \\
\hline Red Seabream & China & 25 & 100 & 0 & 0 & 0 & 37 & 11 & 28 & 65 & 44 & 32 \\
\hline Red Seabream & Japan & 47 & 100 & 59 & 60 & 52 & 36 & 9 & 28 & 72 & 44 & 32 \\
\hline Tiger puffer & Japan & 39 & 100 & 69 & 11 & 60 & 36 & 80 & 28 & 21 & 47 & 3 \\
\hline Tiger puffer & China & 42 & 100 & 66 & 11 & 60 & 37 & 72 & 28 & 84 & 47 & 3 \\
\hline Turbot & Spain & 63 & 100 & 68 & 83 & 44 & 23 & 82 & 51 & 65 & 61 & 73 \\
\hline Turbot & France & 68 & 100 & 68 & 81 & 44 & 52 & 100 & 51 & 67 & 61 & 73 \\
\hline
\end{tabular}

Note: The higher the final score, the better the overall environmental performance.

In contrast, cumulative scores are not expressed per unit production but instead are weighted by total production to reflect the total aggregate effect of that production along that country's coastline. Cumulative scores look at the aggregate effect of an industry: i.e., what is the overall impact of a country's aquaculture industry? Cumulative performance is rarely if ever reported however it is this perspective that confronts policymakers with important questions of industry scale and carrying capacity.

Both normalized and cumulative measures are important. To use an analogy from climate change, $\mathrm{CO}_{2}$ emissions have a minor impact on a normalized basis compared to methane (a mT of methane is orders of magnitude more damaging than a mT of $\mathrm{CO}_{2}$ ). However, the magnitude of $\mathrm{CO}_{2}$ emissions have an earth-changing cumulative impact. As a consequence, governments are attempting to address emissions of both gases. In simplest terms, normalized scores are most relevant for industry while cumulative scores are the only relevant metrics from an ecological perspective (ecological processes do not recognize performance per $\mathrm{mT}$, only cumulative performance).

\section{Results and Discussion}

Sustainability must be demonstrated not assumed. Data availability and quality remain preeminent challenges to any assessment of seafood sustainability. However, verification of the sustainability of any production system requires that abundant, high-quality data are available for analysis. We found data deficiencies to be particularly challenging in the traceability of feedstocks, feed formulation, and the cumulative ecosystem effects of both chemical use and escapes. Currently, determinants of sustainability are typically informed by spotty qualitative data leading to questionable conclusions that may reflect vested interests more than actual performance. The long-term ecological and economic viability of the aquaculture industry depends on shifting policy and production decisions toward quantitatively rigorous, performance-based regulatory frameworks such as GAPI.

Not all marine finfish aquaculture is the same. While it might be reasonable to assume significant performance differences across drastically different types of aquaculture such as shellfish farming and marine finfish farming, GAPI scores reveal tremendous variation in environmental performance just within the marine finfish sector (Figures 1 and 2). These variations are highlighted in species-country pair scores, country scores, and species scores. For instance, normalized species-country scores range from a low of 10 (groupers - Indonesia) to a high of 73 (Chinook salmon - New Zealand). 
Figure 1. Weighted mean country performance expressed as normalized GAPI scores.

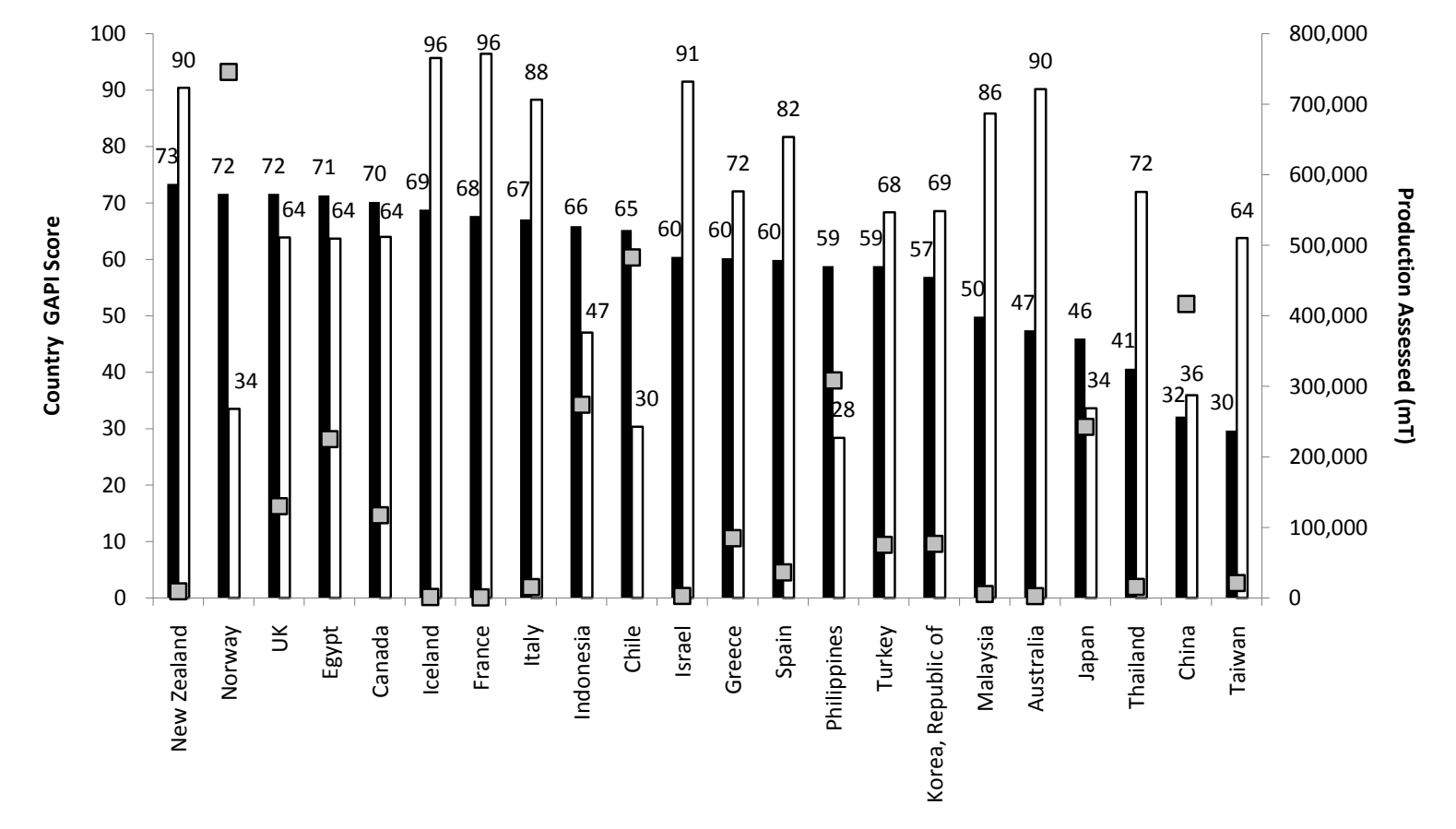

Note: GAPI score per mT production in solid bars; cumulative GAPI scores (score for total production, open bars). Boxes express total production (mT) assessed.

Figure 2. Weighted mean species performance expressed as normalized GAPI scores (performance per mT production; black bars) and cumulative GAPI scores (performance of total global production; open bars). Species arranged by decreasing normalized score.

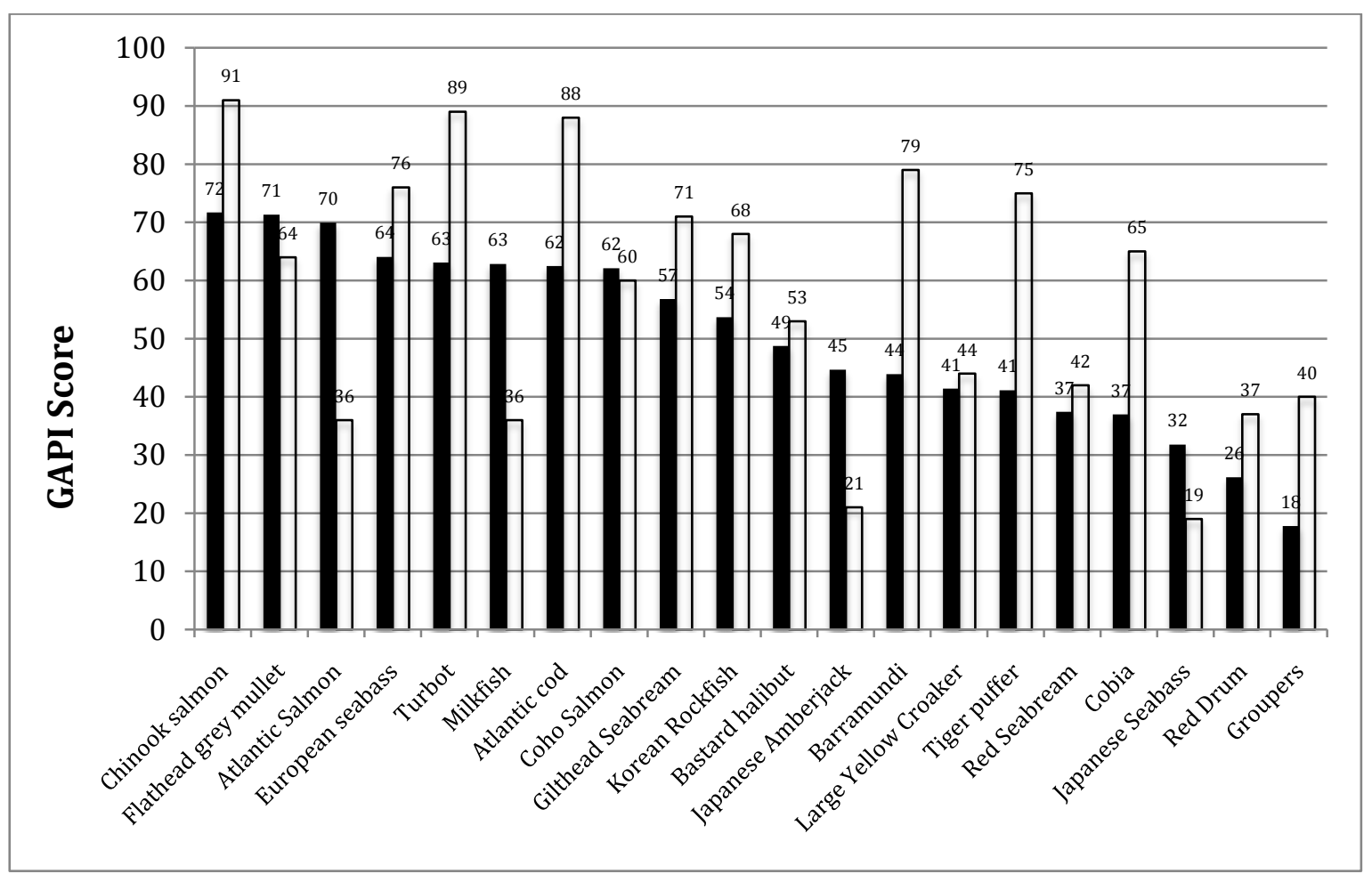


There remains substantial room for improvement. While there is strong variation in GAPI scores across countries and species, and while GAPI does not define pass or failure scores, the findings strongly suggest there is room for improvement within the entire marine finfish sector. Even the best performers are approximately 30 points away from the aspirational target performance of 100 . As aquaculture expands, attention should be paid to ensure that, at a minimum, the industry does not shift further towards the poor performers, at least until performance improve significantly. The worst performing sectors of the industry are also the fastest growing. Marine finfish farmed in tropical and subtropical water, such as groupers (normalized score, 18) red drum (normalized score, 26), and cobia (normalized score, 37), have some of the worst scores on both and normalized and cumulative scales (Figure 3), yet production of these species is currently growing at a rate that outpaces all other species worldwide. Low final scores reflect poor performance across indicators rather than isolated to a few problem areas. In particular, warm water species consume large quantities of feed and receive large amounts of antibiotics, often used prophylactically to mitigate questionable production conditions. We estimate that as much as 5.5 million $\mathrm{Kg}$ of antibiotic materials (bioactive ingredient only, excludes non-active components) may be used annually. This material, much of which is discharged directly to the marine environment, is comprised almost exclusively of compounds classified as "critical" for human and/or veterinary treatment. Indiscriminant and wide-spread use of antibiotics as described here has long been known to critically threaten efficacy of human theraputants. How such threats may be affected by release of active ingredients into the marine food web is unknown [10].

Performance scores only tell some of the story. While the overall GAPI scores are informative, of even greater interest are the differential performances within each indicator that comprise the final score (Table 4). While the overall GAPI scores reflect aggregated performance trends, individual indicators highlight areas where a particular production system may excel and where improvement may be possible. For instance, turbot from Spain and coho salmon from Chile have divergent performance profiles but both have a normalized score of 63 . The turbot scores poorly for antibiotic use (23), only one third the score of coho (68). In contrast, the coho performs poorly with respect to escapes (37) compared to the turbot (61). Similarly, barramundi from Australia and red seabream from Japan both have a normalized species score of 47. Barramundi scores poorly for parasiticides use (30) compared to the red seabream (72). Conversely, the red seabream performs poorly for biological oxygen demand (9), while the barramundi scores reasonably well (62). A key contribution of GAPI (and similarly designed indices) is the capacity to expose root causes inferior performance. In so doing it makes clear that prescriptive solutions such as reduction of parasiticide use will yield far greater benefit for barramundi than red sea bream - where biological oxygen demand is the low hanging fruit in terms of return on investment.

Asia faces significant sustainability hurdles. Asian countries account for the 15 lowest species-country scores (Figure 3). The trend towards lower normalized scores in Asian countries largely results from the prevalence of poor Inputs performance such as ecological and industrial energies, feed sustainability, and biological oxygen demand. Asian countries also tend to score poorly in the antibiotics and parasiticide indicators as GAPI assumes that performers use the maximum allowable dose or quantity in the absence of actual performance data. Given that Asia is and will continue to be the epicenter of aquaculture growth, the observed performance trends should serve as clear warning. 
Figure 3. Final normalized scores plotted against final cumulative scores where products are discriminated by age.

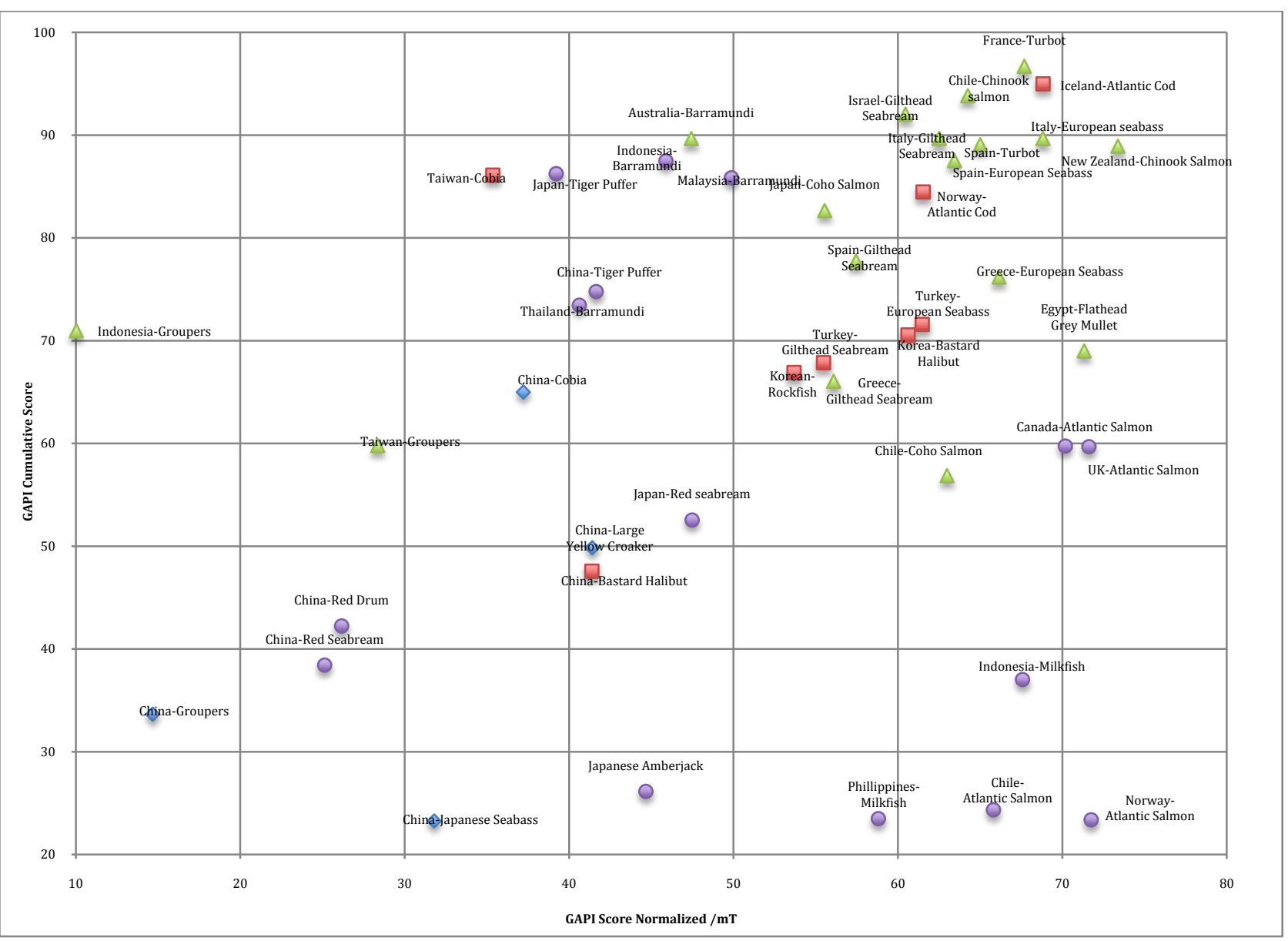

Note: Products in the lower left quadrant are the worst performers on both scales. Products here tend to youngest ( $0-5$ years: blue triangles; 6-20 years: red squares) After 20 years a product is of intermediate age and shows improvement in both normalized and cumulative performance (green triangle). With greater age, gained efficiencies of production drive more production such that the eldest industries ( $<20$ years) are found in the lower right quadrant characterized by the highest normalized scores but among the worst cumulative scores (purple circles).

Atlantic salmon performance illustrates that scale is everything. Comparison of cumulative and normalized scores demonstrates sheer scale of production can have drastic effects on environmental performance. Some of the best-performing species on a normalized basis are among the worst on a cumulative basis (Figure 3 and Table 5). For example, Atlantic salmon is the third-highest ranking species on a per mT basis (normalized score, 70), but when production volume is taken into account, Atlantic salmon score drops almost $50 \%$ to third worst of the 20 assessed species. In contrast, cobia has one of the biggest environmental footprints of any marine finfish (normalized score, 37) and among the worst performers on a per mT basis. However, because cobia farming is currently a modest sized industry it has a relatively small cumulative impact (cumulative score, 65) compared to production leaders Atlantic salmon and milkfish. In other words, there is a tipping point when production efficiencies no longer yield superior environmental performance and can indeed drive performance decline. This raises a question at the heart of seafood sustainability: How do we expand 
aquaculture to support the food and protein needs of 9 billion humans without overwhelming the carrying capacity of the marine environment? Clearly, part of the answer lies in selecting the right species, choosing the right environments in which to grow them, and utilizing responsible farming practices. At the same time, regulators need to consider the double-edged nature of production efficiency and how such efficiency, regarded as an industry objective, can lead to unanticipated problems. When normalized performance is plotted as a function of cumulative performance an inverted horseshoe pattern emerges (Figure 3). The left terminus of the horseshoe (poor normalized and cumulative scores) are the youngest products still in the "trial and error" phase of development. The right terminus is comprised of the oldest players, those products that enjoy high normalized performance and as a result have proliferated greatly resulting in large scale production and decline cumulative scores. The belly of the horseshoe (intermediate normalized and cumulative scores) are intermediate aged players that have found some production success but have yet to leverage that into large scale production. Policy decisions informed solely by normalized performances are likely to perpetuate this trend. However it is important to reiterate that normalized performance is irrelevant to the environment. The only environmentally relevant metric is cumulative performance.

Table 5. The ranking of country-species pairs by normalized and cumulative scores.

\begin{tabular}{|c|c|c|c|c|c|c|}
\hline \multirow{2}{*}{ Country-Species } & \multicolumn{2}{|c|}{ Normalized } & \multicolumn{2}{|c|}{ Cumulative } & \multirow{2}{*}{$\begin{array}{c}\% \text { Global Marine } \\
\text { Finfish Production }\end{array}$} & \multirow{2}{*}{$\begin{array}{c}\text { Difference } \\
\text { Cum-Norm }\end{array}$} \\
\hline & Rank & GAPI score & Rank & GAPI score & & \\
\hline New Zealand-Chinook salmon & 1 & 73 & 5 & 90 & 0.27 & 17 \\
\hline Norway-Atlantic Salmon & 2 & 72 & 38 & 33 & 21.00 & -39 \\
\hline UK-Atlantic Salmon & 3 & 72 & 28 & 64 & 3.70 & -8 \\
\hline Egypt-Flathead grey mullet & 4 & 71 & 29 & 64 & 6.41 & -8 \\
\hline Canada-Atlantic Salmon & 5 & 70 & 27 & 64 & 3.30 & -6 \\
\hline Iceland -Atlantic cod & 6 & 69 & 2 & 96 & 0.04 & 27 \\
\hline Italy-European seabass & 7 & 69 & 7 & 89 & 0.24 & 20 \\
\hline France-Turbot & 8 & 68 & 1 & 96 & 0.02 & 29 \\
\hline Indonesia-Milkfish & 9 & 68 & 34 & 46 & 7.49 & -22 \\
\hline Greece-European seabass & 10 & 66 & 17 & 77 & 1.00 & 11 \\
\hline Chile-Atlantic Salmon & 11 & 66 & 42 & 23 & 10.80 & -43 \\
\hline Italy-Gilthead Seabream & 12 & 65 & 9 & 88 & 0.20 & 23 \\
\hline Chile-Chinook salmon & 13 & 64 & 3 & 94 & 0.06 & 30 \\
\hline Spain-European seabass & 14 & 63 & 10 & 87 & 0.26 & 24 \\
\hline Chile-Coho Salmon & 15 & 63 & 32 & 57 & 2.90 & -6 \\
\hline Spain-Turbot & 16 & 63 & 8 & 88 & 0.19 & 26 \\
\hline Norway-Atlantic cod & 17 & 62 & 11 & 87 & 0.27 & 25 \\
\hline Turkey-European seabass & 18 & 61 & 21 & 70 & 1.19 & 9 \\
\hline Korea-Bastard halibut & 19 & 61 & 22 & 69 & 1.17 & 8 \\
\hline Israel-Gilthead Seabream & 20 & 60 & 4 & 91 & 0.08 & 31 \\
\hline Phillippines-Milkfish & 21 & 59 & 41 & 28 & 8.78 & -30 \\
\hline Spain-Gilthead Seabream & 22 & 57 & 18 & 77 & 0.58 & 20 \\
\hline Greece-Gilthead Seabream & 23 & 56 & 23 & 68 & 1.42 & 12 \\
\hline Japan-Coho Salmon & 24 & 56 & 16 & 80 & 0.38 & 25 \\
\hline
\end{tabular}


Table 5. Cont.

\begin{tabular}{|c|c|c|c|c|c|c|}
\hline \multirow{2}{*}{ Country-Species } & \multicolumn{2}{|c|}{ Normalized } & \multicolumn{2}{|c|}{ Cumulative } & \multirow{2}{*}{$\begin{array}{c}\% \text { Global Marine } \\
\text { Country-Species }\end{array}$} & \multirow{2}{*}{$\begin{array}{l}\text { Difference } \\
\text { Rank }\end{array}$} \\
\hline & Rank & GAPI score & Rank & GAPI score & & \\
\hline Turkey-Gilthead Seabream & 25 & 55 & 26 & 66 & 0.95 & 10 \\
\hline Korea-Korean Rockfish & 26 & 54 & 24 & 68 & 1.01 & 15 \\
\hline Malaysia-Barramundi & 27 & 50 & 13 & 86 & 0.16 & 36 \\
\hline Japan-Red seabream & 28 & 47 & 33 & 50 & 1.91 & 2 \\
\hline Australia-Barramundi & 29 & 47 & 6 & 90 & 0.07 & 43 \\
\hline Indonesia-Barramundi & 30 & 46 & 12 & 86 & 0.13 & 41 \\
\hline Japan-Japanese Amberjack & 31 & 45 & 43 & 21 & 4.49 & -23 \\
\hline China-Tiger puffer & 32 & 42 & 19 & 72 & 0.43 & 31 \\
\hline China-Large Yellow Croaker & 33 & 41 & 35 & 44 & 1.76 & 2 \\
\hline China-Bastard halibut & 34 & 41 & 36 & 43 & 1.89 & 1 \\
\hline Thailand-Barramundi & 35 & 41 & 20 & 72 & 0.45 & 31 \\
\hline Japan-Tiger puffer & 36 & 39 & 14 & 85 & 0.12 & 46 \\
\hline China-Cobia & 37 & 37 & 30 & 62 & 0.74 & 24 \\
\hline Taiwan-Cobia & 38 & 35 & 15 & 84 & 0.11 & 49 \\
\hline China-Japanese Seabass & 39 & 32 & 44 & 19 & 2.86 & -13 \\
\hline Taiwan-Groupers & 40 & 28 & 31 & 59 & 0.49 & 31 \\
\hline China-Red Drum & 41 & 26 & 37 & 37 & 1.40 & 10 \\
\hline China-Red Seabream & 42 & 25 & 39 & 33 & 1.56 & 8 \\
\hline China-Groupers & 43 & 15 & 40 & 29 & 1.22 & 14 \\
\hline Indonesia-Groupers & 44 & 10 & 25 & 68 & 0.18 & 58 \\
\hline
\end{tabular}

Note: The differential is most pronounced in those with the greatest or least production. The far right column highlights the importance of how assessments are carried out; some of the best-performing species on a normalized basis are among the worst on a cumulative basis.

\section{Conclusions}

The GAPI analysis allows us to identify why products score poorly, suggest how their peers have addressed the same challenges and provide insight in policy-relevant contexts ready for decision makers to take action. These initial results beg the question: how does aquaculture grow in a way that both supports the global food industry and mitigates local environmental damage? Part of the answer lies in carefully selecting which species we will farm and in choosing the right environments in which to grow them (i.e., reducing normalized scores). At the same time, regulators need to consider the carrying capacity of local waters, and begin to design and reward operations that demonstrably minimize environmental footprint. Time is of the essence, however. The most current production data available (2011) reveal global marine aquaculture grew 22\% [11] during the brief life of this project which began in 2009. The qualitative profile of production has remained constant over this period; both relative ranking of species and production countries have remained stable however the overall scale of production continues to rise rapidly. Therefore, while many of the revelations revealed by the GAPI project are sobering, this current analysis should be interpreted as a conservative snapshot of current industry performance.

GAPI is a work in progress and is intended to both inform and stimulate discussion of the appropriate metrics for evaluating performance and to drive the gathering and sharing of data. We are 
hopeful that GAPI will transform the way environmental performance is assessed and will aid decision makers-policymakers, producers, buyers, or standard setters-as they continue to address the promise and challenges of marine aquaculture.

\section{Acknowledgments}

This work was financially supported by the Lenfest Oceans Program and Pew Environmental Trusts and came to fruition through the dedication and leadership of Chris Mann and Rachel Hopkins. We recognize the EPI research group for initial inspiration of this work. We thank Katherine Bostick, Peter Bridson, Carrie Brownstein, Alice Chiu, Matthew Elliot, Rebecca Goldburg, George Leonard, Corey Peet, and Helene York for their many contributions to the development of the GAPI approach and resultant tool. We thank Vicki Blazer, Claude Boyd, Alejandro Bushmann, Alex de Sherbinin, Daniel Esty, Jennifer Ford, Christine Kim, Kevin Lafferty, Astrid Sholtz, Tanja Srebotnjak, Peter Tyedmers, and Judith Weis for their thoughtful contributions and advice in building criteria-specific assessment modules.

\section{Supplementary Materials}

Appendices can be accessed at: http://www.mdpi.com/2071-1050/5/9/3976/s1.

Raw data and additional analyses can be accessed at: Global Aquaculture Performance Index (http://web.uvic.ca/ gapi/).

\section{Conflicts of Interest}

The authors declare no conflict of interest.

\section{References}

1. Food and Agriculture Organization (FAO). The State of World Fisheries and Aquaculture 2002; FAO Fisheries Department: Rome, Italy, 2003.

2. Hall, S.J.; Delaporte, A.; Phillips, M.J.; Beveridge, M.; O’Keefe, M. Blue Frontiers: Managing the Environmental Costs of Aquaculture; The WorldFish Center: Penang, Malaysia, 2011.

3. Scottish Executive Research Unit. Review and Synthesis of the Environmental Impacts of Aquaculture; Government of Scotland: Edinburgh, Scotland, 2002.

4. Phillips, S. Environmental Impacts of Marine Aquaculture Issue Paper; Pacific States Marine Fisheries Commission: Portland, OR, USA, 2005.

5. Jacquet, J.; Hocevar, J.; Lai, S.; Majluf, P.; Pelletier, N.; Pitcher, T.; Sala, E.; Sumaila, R.; Pauly, D. Conserving wild fish in a sea of market-based efforts. Orynx 2009, 44, 45-56.

6. Emerson, J.W.; Hsu, A.; Levy, M.A.; de Sherbinin, A.; Mara, V.; Esty, D.C.; Jaiteh, M. Environmental Performance Index and Pilot Trend Environmental Performance Index; Yale Center for Environmental Law and Policy: New Haven, CT, USA, 2012.

7. Food and Agriculture Organization (FAO). FishStat Plus: Universal Software for Fishery Statistical Time Series; FAO: Rome, Italy. Available online: http://www.fao.org/fishery/statistics/software/ fishstat/en (accessed on 15 November 2010). 
8. Emerson, J.; Esty, D.; Levy, M.; Kim, C.; Mara, V.; de Sherbinin, A.; Srebotnjak, T. Environmental Performance Index; Yale Center for Environmental Law and Policy: New Haven, CT, USA, 2010.

9. Singh, R.; Murty, H.; Gupta, S.; Dikshit, A. An overview of sustainability assessment methodologies. Ecol. Indicat. 2009, 9, 189-212.

10. Cabello, F. Heavy use of prophylactic antibiotics in aquaculture: A growing problem for human and animal health and for the environment. Environ. Microbiol. 2006, 8, 1137-1144.

11. Food and Agriculture Organization (FAO)-FIGIS. Available online: http://www.fao.org/fishery/ figis/en (accessed on 2 May 2010).

(C) 2013 by the authors; licensee MDPI, Basel, Switzerland. This article is an open access article distributed under the terms and conditions of the Creative Commons Attribution license (http://creativecommons.org/licenses/by/3.0/). 